\title{
In Situ Evaluation of the Factors Controlling Carbon Nanotube Synthesis During Catalytic Chemical Vapor Deposition
}

\author{
Renu Sharma
}

Center for Nanoscale Science and Technology, National Institute of Science and Technology, Gaithersburg, MD 20899-6203

Carbon nanotubes are one of the most versatile materials with numerous applications in, highperformance composites, energy storage devices, micromachines, scanning probe microscopy, nanocircuits, elements of biosensors, and much more. However, many of these rely on having control over their structure and placement. Catalytic chemical vapor deposition using transition metal catalysts, such as $\mathrm{Ni}, \mathrm{Co}$ and $\mathrm{Fe}$, is one of the most frequently used methods for their largescale synthesis. In recent years, several in situ observations have been used to reveal their formation mechanisms during catalytic chemical vapor deposition (C-CVD). [1-3] We have used the sample area of an environmental scanning transmission electron microscope (ESTEM) as a flow reactor [4] to evaluate the effect of temperature, pressure and the nature of catalyst on the structure, morphology, and yield of CNTs. The results of those studies are reported here.

The general experimental conditions used to follow CNT growth process can be described as follows: $\mathrm{Ni}, \mathrm{Au}-\mathrm{Ni}$, or Fe catalyst particles, synthesized in situ or ex situ, on $\mathrm{SiO}_{2}$ supports were loaded on TEM grids and heated to the growth temperature of $480 \mathrm{C}$ to $700 \mathrm{C}$ using a furnace heating holder equipped with a thermocouple. Approximately $0.13 \mathrm{~Pa}$ to $14 \mathrm{~Pa}$ of acetylene $\left(\mathrm{C}_{2} \mathrm{H}_{2}\right)$ was then leaked in the sample area and high resolution digital videos were recorded with a time resolution of 15 frames per second. The structure and morphology of CNTs formed during in situ experiments were further characterized by ex situ TEM imaging and electron energy-loss spectroscopy (EELS).

There are a number of factors, such as choice of catalyst, support, precursor, synthesis conditions (temperature and pressure), that control the structure (single-walled or multi-walled), morphology (length and diameter) of CNTs formed. FIG. 1 shows that for $\mathrm{Ni} / \mathrm{SiO}_{2}$, multi-walled CNTs (MWCNTs) grow in zigzag manner at $480 \mathrm{C}$ in $13 \mathrm{~Pa}$ of flowing $\mathrm{C}_{2} \mathrm{H}_{2}$ via a tip-growth mechanism, resulting in a tangled web of MWCNTs. [5] The yield of CNT formation can be increased by doping Ni with small amount (below $20 \%$ mole fraction) of Au. (FIG. 2) The carbon nanostructures also change from MWCNTs to herring-bone carbon nanofibers with Au doping (see inset in Figure 2). The mechanism of nucleation of a CNT on the surface of a catalyst particle and its subsequent lift off can be obtained from high resolution images as shown in FIG. 3. Low $\mathrm{C}_{2} \mathrm{H}_{2}$ pressure $(0.13 \mathrm{~Pa}$ to 0.19 $\mathrm{Pa})$ and high temperature $(<600 \mathrm{C})$ were observed to favor the formation of straight single-walled CNTs (SWCNTs) via a tip-growth mechanism (FIG. 4). However, for $\mathrm{Au}$ doped Ni, higher temperatures $(<700 \mathrm{C})$ were required to form SWCNTs. We show that in situ observations can be used to optimize parameters for selective synthesis of CNTs tailored for any given application.

References

[1] S. Helveg et al, Nature 427 (2004) 426.

[2] R. Sharma \& Z. Iqbal, Appl. Phys. Lett. 84 (2004) 990S

[3] Yoshida at al., Nano Letters 8 (2009) 2082.

[4] R. Sharma, J. Mater. Res. 20 (2005) 1695

[5] R. Sharma et al, Nanotechnology 18 (2007) 125602 
[7] The use of facilities in the LeRoy Eyring Center for Solid State Science at Arizona State University is gratefully acknowledged
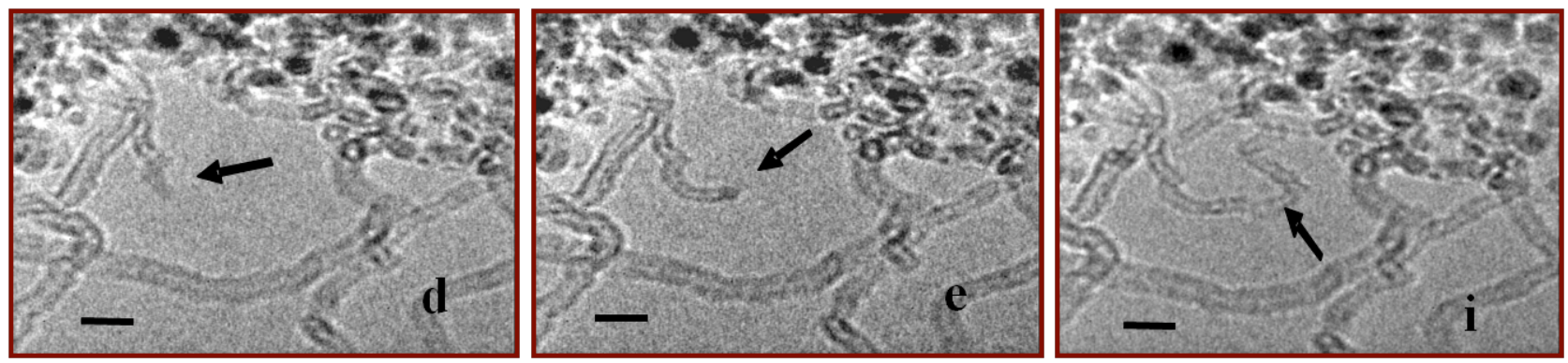

FIG. 1. Time resolved, low magnification images extracted from a video recorded at $480{ }^{\circ} \mathrm{C}$ in $\approx 13 \mathrm{~Pa}$ of $\mathrm{C}_{2} \mathrm{H}_{2}$ showing the zigzag growth of a MWCNT from $\mathrm{Ni} / \mathrm{SiO}_{2}$ catalyst via tip growth mechanism. Bar is $10 \mathrm{~nm}$.

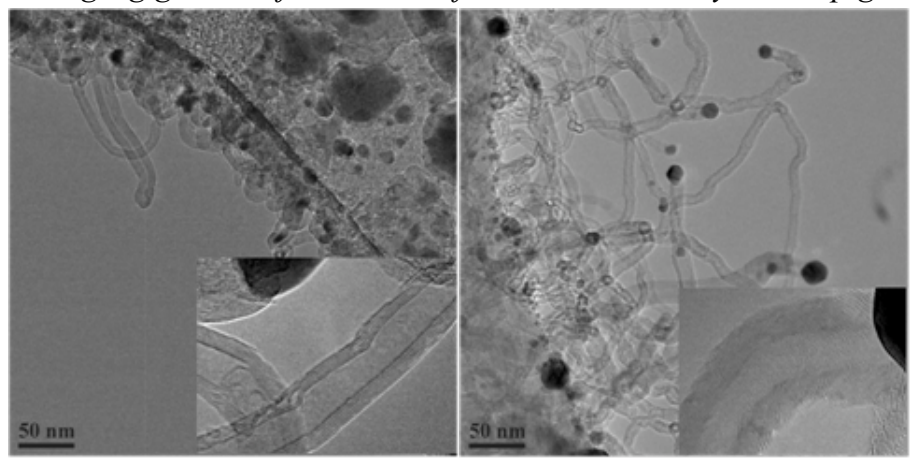

FIG.1. Effect of Au doping: Ex-situ images recorded after in situ growth showing the increased yield of MWCNTs for Ni catalyst doped with 20 mole fraction of Au compared to Ni after samples were exposed to $\approx 0.2 \mathrm{~Pa}$ of $\mathrm{C}_{2} \mathrm{H}_{2}$ at $520{ }^{\circ} \mathrm{C}$. Inset in both images shows formation of MSCNT for pure Ni and CNF with herring bone structure for Au doped Ni.
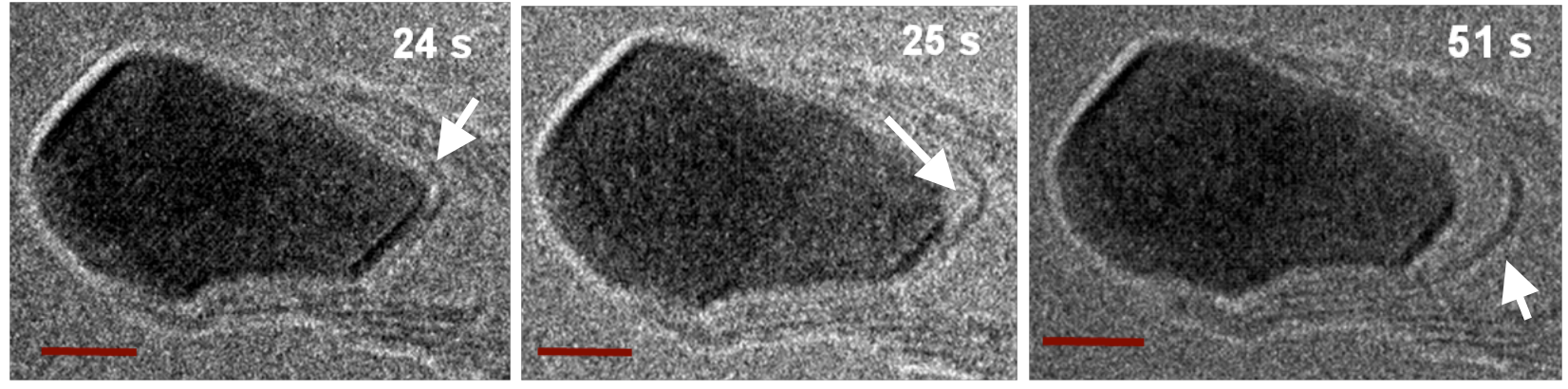

FIG. 3. High resolution images showing the growth mechanism of carbon nanofibers from Au doped $\mathrm{Ni}_{\mathrm{c}}$ atalyst on $\mathrm{SiO} \mathrm{O}_{2}$ support at $520{ }^{\circ} \mathrm{C}$ in $\approx 0.2 \mathrm{~Pa}$ of $\mathrm{C}_{2} \mathrm{H}_{2}$. Nucleation and lift-off of an internal nanotube (marked by arrows) is accompanied by the particle shape change and provides an insight into the growth mechanism for a SWCNT.
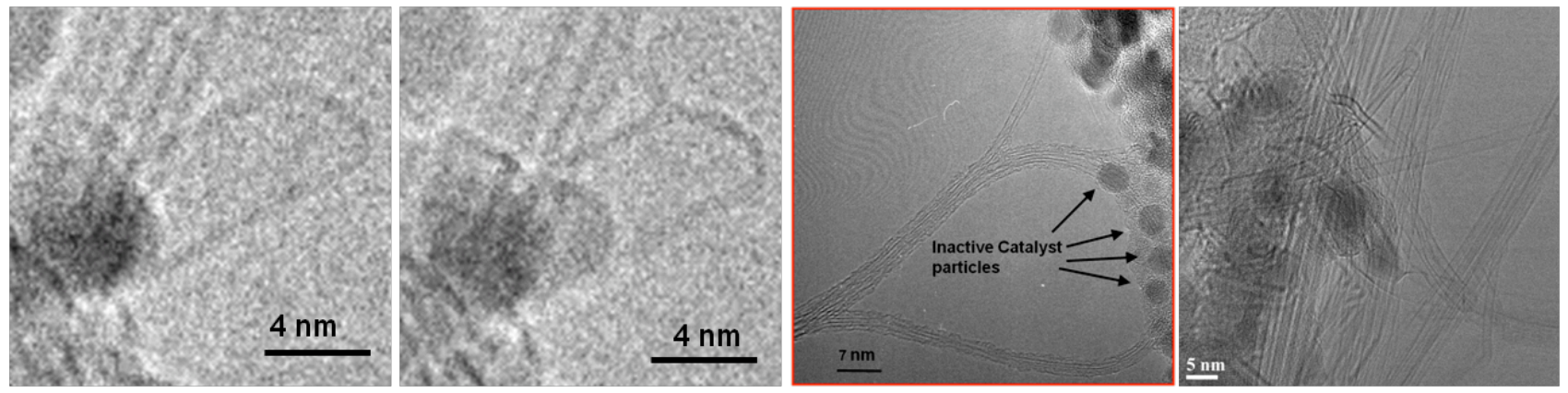

FIG. 4. (a) A SWCNT grew from the tip of the catalyst particle; (after) one second the particle was sucked in the tube and took the shape of the tube. (c-d) Single walled tubes formed at $650{ }^{\circ} \mathrm{C}$ from $\mathrm{Ni} / \mathrm{SiO}_{2}$ and $\mathrm{Fe} / \mathrm{SiO} \mathrm{O}_{2}$ catalyst in $\approx 0.13$ $\mathrm{Pa}$ and of $\mathrm{C}_{2} \mathrm{H}_{2}$ and $\approx 0.2 \mathrm{~Pa}$, respectively. 